\title{
Las oraciones de relativo y la definitud de su antecedente expreso
}

\author{
Relative clauses and the definiteness \\ of their head noun phrases
}

\author{
Janusz Pawlik \\ Uniwersytet im. Adama Mickiewicza, Poznań \\ pawlik@amu.edu.pl
}

\begin{abstract}
The paper is concerned with the (in)definite reference of a noun phrase which is the head of a relative clause in Spanish. Speaker and hearer do not share any knowledge of the referent on the basis of previous mention (anaphora) or situational uses. There is something about the relative clause which makes a first-mention definite article possible. We take an insight into the contents of the description conveyed by such relatives.
\end{abstract}

Keywords: relative clause, (in)definiteness of a head noun phrase, first-mention definite article, identification of a referent

\section{1. (IN)DEFINITUD DE UN GN MODIFICADO POR UNA SUBORDINADA DE RELATIVO}

La referencia del sustantivo que encabeza a una subordinada relativa obedece a reglas comunes que regulan el uso del artículo en otros contextos. Hay también ciertas particularidades exclusivas de esta construcción. En la presente contribución se propone poner de manifiesto algunos condicionantes propios de la cláusula relativa que repercuten en la referencia de su cabeza (factores internos). Las subordinadas relativas restrictivas, como otros modificadores, producen dos efectos: el primero genera la determinación y el segundo la indeterminación del grupo nominal 
(GN) correspondiente. Veremos en qué consisten las diferencias en su interpretación. Consideremos, para empezar, dos secuencias:

Ese es el hombre que encontré ayer.

Ese es un hombre que respeto enormemente.

Ambas describen referentes existenciales y concretos. En la segunda frase la indefinitud del GN (un hombre que...) puede acompañarse del conocimiento del individuo al que presentamos como sujeto. Por otro lado, la identificación llevada a cabo en la primera frase no tiene que resultar de la familiaridad del oyente con el referente (Brucart 1999). El destinatario podrá desconocer al hombre que el emisor dice haber encontrado. En palabras de Leonetti (1999b: 791-792):

El hablante puede usar una descripción definida para referirse a un objeto no mencionado previamente ni integrado en el universo discursivo, simplemente porque espera que su interlocutor sea capaz de inferir la existencia del referente, aunque se trate de un objeto no conocido ni familiar.

El autor concluye en otro lado que „El rasgo central de las expresiones definidas no es, por tanto, el conocimiento previo del objeto por parte del receptor, sino la identificabilidad del referente, es decir, la presuposición de que el receptor puede construir una representación mental adecuada del mismo" (Leonetti 1999a: 39). ¿En qué consiste el carácter identificador de una relativa respecto a su antecedente nominal? Es cuestión poco atendida en estudios de la materia que interesa máxime a los hablantes de ELE cuyos idiomas nativos no poseen artículos.

\section{RELATIVAS IDENTIFICATIVAS SIN MENCIÓN PREVIA}

¿Cómo valorar la información transmitida por una cláusula subordinada? Hawkins (1978) denomina las cláusulas que pueden aparecer desde su primera mención con artículo definido (AD) singular establishing relatives, como en ${ }^{1}$ :

What's wrong with Bill?

Oh, the woman he went out with last night was nasty to him. (1)

Por contra, no se pueden usar sin anáfora los GN definidos con una relativa restrictiva de otra estructura (non establishing relative), p. ej.:

The woman who was from the south was nasty to him. (2)

\footnotetext{
${ }^{1}$ En las frases inglesas recogidas, el artículo aparece en singular y muestra un comportamiento parecido a las reglas vigentes en español.
} 
El autor lo explica así:

The impossibility of (2) functioning as a first-mention definite description follows from the fact that the relative clause is predicting some property of the woman in question, whereas in (1) the relative places the woman in some relation to Bill. [...] It seems that establishing relatives must relate the new, definite referent either to some previously known object, or to participants in the talk-exchange, or to objects in the immediate situation (Hawkins 1978: 132-134).

En lo relativo al francés, Wilmet (1986: 59) cita un ejemplo parecido, en el que la definitud de la frase nominal es impuesta por el contexto endofórico (ASALE 2009), esto es, por la característica referencial de la subordinada correspondiente:

La fille que Bill a invitée hier soir me plaît.

Lyons (1999) declara, a su vez, que este uso del artículo definido debe clasificarse como efecto de la catáfora.

Pese a la aceptabilidad de (1), Hawkins (1978: 225) admite también como viable la secuencia en que el antecedente quedará indefinido, y todo ello sin alterar su interpretación pragmática:

What's wrong with Bill? Oh, a woman he went out with last night was nasty to him. (3)

Riley (2008: 46), por su parte, aduce frases parecidas con alternancia referencial, afirmando que el empleo del artículo indefinido (AI) supondrá inevitablemente el aislamiento de un individuo de entre más entidades:

The woman I saw you with last night called me this morning.

= I saw you with a woman last night.

A woman I saw you with last night called me this morning.

$=\mathrm{I}$ saw you with some women last night.

Nótese que las frases the woman I saw you with last night y (3) a woman he went out with last night son semánticamente distintas pese a su coincidencia sintáctica. Ambas pueden aparecer sin mención anterior con referencia a una persona. La diferencia reside en la capacidad identificadora de la relativa, la cual es mayor en el primer ejemplo (AD) que en el segundo (AI). El factor decisivo es el pronombre you, que apela directamente a la memoria del destinatario, a los acontecimentos de los que fue testigo o participante. El argumento he (Bill) y el adjunto last night, mencionados en la segunda frase, no apuntan de forma tan tajante a la unicidad situacional del referente. Corblin (1987) presenta un GN con AD de primera mención:

La femme que tu as rencontrée ce matin est jolie. 
Como vemos, de nuevo, el autor francés echa mano a una subordinada dirigida a la esfera del oyente que tu as rencontrée ce matin, asignándole la mayor carga indentificativa, es decir, la que apela sin intermedios al mundo cognoscitivo del receptor.

Siguiendo a Kleiber (1981: 219), no poseen capacidad identificativa las oraciones que él denomina non spécifiantes: „Ce sont tous des prédicats qui décrivent une propriété, un attribut du référent. [...] n'impliquent aucune localisation externe, aucun point de référence spatio-temporel, ou, si l'on préfère, leur sens ne requiert pas le recours au hic et nunc de l'énonciation". Tales expresiones responden a la pregunta ¿qué tipo? y se introducen en el discurso con un AI:

J'ai recontré une fille qui parle le basque.

J'ai recontré une femme qui a les cheveux roux.

J'ai recontré une fille qui est jolie.

Kleiber (1981) apunta, no obstante, que los GN con predicados no especificantes (o de propiedades) no son compatibles en primera mención con el predicado de la cláusula principal del mismo tipo. Así:

*Une fille qui a les cheveux roux parle le basque ${ }^{2}$.

Esta oración puede encabezarse solo con $\mathrm{AD}$, pero entonces la definitud viene de un contexto anafórico o situacional. Las propuestas de Hawkins (1978) y Kleiber (1981) se parecen a la división de los predicados en stage-level predicates e individual-level predicates elaborada por Carlson (1980).

Leonetti (1991: 177) hace notar que "En especial, resultan anómalas las oraciones que contienen sujetos indefinidos con predicados negativos o, en general, no especificantes, es decir, predicados que no proporcionan las coordenadas espaciotemporales necesarias para la localización de un referente":

*Una amiga no rompió un vaso.

*Un hombre es viejo.

Es difícil delimitar un objeto o un subconjunto de objetos a partir de propiedades que no permitan distinguirlos. Estas combinaciones son aceptables solo en dos casos: cuando la oración puede entenderse como genérica, y cuando el hablante presenta al sujeto como entidad existencial. Ejemplos:

Un hombre es mortal.

Un vecino mío sabe escribir en chino.

\footnotetext{
${ }^{2}$ Dicha oración se hace correcta si se profiere en un contexto anafórico [Deux filles sont lá] Une fille qui a les cheveux roux parle le basque, et l'autre l'italien. En su primera mención, solo se admite tal construcción en un sentido genérico (Leonetti 2013).
} 
Si la oración es genérica ya no es necesario extraer referente alguno del conjunto denotado, y si el SN indefinido es fácilmente interpretable como referencial (uno de mis vecinos), se infiere que existe un referente específico que debe ser delimitado y extraído del conjunto de partida (Leonetti 1991). Con relación al inglés esta cuestión ha sido abordada previamente por Milsark (1974, 1977).

\section{CARÁCTER IDENTIFICADOR DE UNA RELATIVA: UN CASO DE PRONOMBRE PERSONAL}

El problema es que muchas relativas cuyos predicados deben clasificarse como 'especificantes' (establishing o stage-level predicates), es decir, propicios para la definitud de un GN sin mención previa, tampoco llevan a cabo tal identificación de sus GN correspondientes, p. ej.:

Leo un libro que me ha prestado Fernando.

Je lis un livre que ma soeur m'a donné.

A woman who knew John brought him to the party.

Ni Kleiber, ni Hawkins, ni autores posteriores prestan la debida atención a este problema, cuestión de primera magnitud para los aprendientes de español de lengua materna polaca.

¿Qué factores inciden, pues, en el carácter identificador de una relativa? Por lo general, los argumentos de carácter definido (nombres propios, pronombres personales, nombres comunes definidos), adverbios y frases adverbiales de lugar (aquí, allí, en la calle Alcalá), adverbios y frases adverbiales de tiempo (en 1960, el martes, hasta ayer) tienden a exigir la presencia de un artículo definido (Pawlik 2019; Leonetti 2012). En cambio, por ejemplo, las construcciones impersonales no llegan a cumplir habitualmente con el requisito de unicidad del antecedente. Comparemos:

Tengo que leer los libros que me compró el maestro.

Tengo que terminar los trabajos que he empezado.

Hay que leer libros que se ha comprado.

Hay que terminar trabajos que se han empezado.

Parece que entre los pronombres personales relacionados con el verbo de la subordinada son tú/vosotros/usted/ustedes y nosotros quienes demuestran mayor capacidad descodificadora ${ }^{3}$. Cotéjense dos secuencias con GGNN tomadas de Kleiber (1981) y Corblin (1987) levemente modificadas:

Une femme que j'ai recontrée ce matin vient me voir.

La femme que tu as rencontrée ce matin vient me voir.

\footnotetext{
${ }^{3}$ Todos ellos encierran en sí la persona del receptor del comunicado.
} 
J'ai rencontré une femme qui me plaît.

J'ai recontré la femme qui nous plaît.

En las frases transcritas la diferencia de definitud apreciada en los GN resulta de la fuerza identificadora de argumentos orientadores que se encuentran en la subordinada (tú y yo). El primero es más reconocible para el oyente, ya que se aplica a él. Adviértase asimismo que el pronombre personal nosotros puede abarcar tanto al emisor como al receptor, de ahí su alta capacidad de reconocer el referente denotado.

He aquí dos oraciones españolas que involucran la esfera del oyente en la representación situacional del objeto denotado:

Estos son los libros de los que te he hablado.

Me refiero a la película que nos ha inspirado.

Nótese que por compartir el emisor y destinatario(s) del comunicado una experiencia común se puede percibir el sintagma la película como algo reconocido y único (y por ello identificado), lo que le asigna el rasgo de definitud.

Pero la mera inclusión de la persona del receptor en el contenido de la subordinada no garantiza que todo el GN se vuelva identificable sin ser nombrado antes. Veamos una misma frase en inglés y español:

A woman you know went out with Bill last night.

Una mujer que conoces salió con Bill anoche.

La relativa no acaba de identificar el GN, ya que, aun perteneciendo a las establishing relatives y contando con el pronombre adecuado, no es capaz de discriminar una persona única y concreta. Se presupone, en cambio, un grupo de personas conocidas por el receptor (se suele 'conocer a más de una mujer'). De ello se concluye que no es cuestión de un empleo irreflexivo de las categorías vinculadas con la esfera de los interlocutores (tú, vosotros, nosotros) lo que asegura la lectura definida de un GN complementado. En general, el personal tú resulta insuficiente en ausencia de una identificación cuantitativa, es decir, en el caso de argumentos que suelen aparecer en varios ejemplares. Lo observamos en una frase como escribir libro(s):

Vi un libro que has escrito.

Como se comprueba, el hablante trata el argumento solo de forma clasificativa, sin extraer un referente único ${ }^{4}$. Deja así la posibilidad de existir más libros del autoroyente. De otro lado

Vi el libro que has escrito

\footnotetext{
${ }^{4}$ Veamos que se puede escribir muchos libros, mientras que es posible amar, en el momento dado, solo a una mujer, p. ej. Por la mañana me he encontrado a la mujer de la que estás enamorado.
} 
da a entender que el emisor de la frase presupone la existencia del libro y/o lo presenta como el único de este autor. En tal caso, el interlocutor está en condiciones de identificar sin falta el libro comentado. A veces, las cláusulas que incorporan un GN identificado previamente pueden adoptar un carácter clasificador, a pesar de la unicidad de su referente. El GN se revela entonces como portador de unas propiedades especiales puestas de relieve en la subordinada, p. ej.:

Vender tu obra, un libro que has escrito con mucho esfuerzo y pasión, por suerte, nunca había sido tan fácil como ahora con las plataformas digitales.

$\underline{T u \text { esposo }}$ te respeta y te deja tomar las decisiones que tú consideres correctas [...]. $\underline{U n}$ hombre que te ama profundamente ama cada detalle de ti, hasta los que tú consideras imperfecciones.

En tales casos se desvanece el contenido de cuantificación perceptible antes. Estamos, en efecto, ante secuencias clasificativas con una correferencia anafórica respecto a su antecedente discursivo (ASALE 2009). Como la información contenida en la adjetiva destaca un tipo especial de libro y una especie de hombre, es conveniente ver en este uso una categorización valorativa del referente en cuestión.

\section{LA REFERENCIA (IN)DEFINIDA Y LA CUANTIFICACIÓN DE UN GN}

Hemos comprobado que en la referencia nominal suele reflejarse la proyección cuantitativa de un referente. El factor numérico debe tomarse en cuenta en la situación pragmática de cualquier referente, también sin modificador oracional. Si decimos:

La carne de pollo es la excepción,

damos a entender que no se admiten más excepciones, sino esta única. En suma, la relación de igualdad uno a uno entre los dos argumentos es la que propicia la aparición del $\mathrm{AD}$. Considérense los GN con relativa restrictiva en otras oraciones copulativas:

$\mathrm{X}$ y Y son libros que ha escrito Borges.

$\mathrm{X}, \mathrm{Y}, \mathrm{Z}$ y V son los libros que ha escrito Borges.

En función de la relación numérica que se dé entre sujeto y atributo, una misma oración puede obtener interpretaciones distintas. La primera va marcada con AI (cero) y designa que el conjunto de entidades representado por el sujeto se incluye dentro de un conjunto mayor, denotado por el atributo. La relación cuantitativa entre sujeto y atributo se ve igualada en el segundo ejemplo, donde los referentes desig-

\footnotetext{
${ }^{5}$ De aquí en adelante, hacemos caso omiso de los indefinidos unos/unas, aceptables en algunos ejemplos.
} 
nados por el sujeto corresponden en número a las unidades reflejadas por el atributo. El contraste PARCIAL $\sim$ TOTAL $^{6}$ se revela como el contenido clave responsable de la variación del artículo en dichas estructuras. Es de recordar que para Leonetti (1999b), los grupos indefinidos muestran aquí una referencia exclusiva, mientras que los definidos, una referencia inclusiva (términos de Hawkins 1978). Resumiendo, conviene concluir que el AD representa en oraciones copulativas así modificadas (y en otras) un valor identificativo-totalizador, y su falta anuncia una lectura clasificativo-parcial ${ }^{7}$. En la teoría de la predicación, las copulativas expuestas se definen como identificativas y se admite que sus atributos pueden admitir una lectura 'débilmente referencial' (GDLE 1999).

Obsérvese que al aportar un dato cronológico suplementario a la subordinada obtenemos la misma interpretación parcial del GN. Por ejemplo:

X y Y son libros que escribió Borges en 1967.

“Crónicas de Bustos Domecq" es un libro que escribió Borges en 1967.

El conjunto nominal ni en singular ni en plural logra ser identificado por defecto mediante la subordinada en cuestión, dejando dos valores de referencia disponibles: clasificativo-parcial $(u n / \varnothing)$ e identificativo-totalizador $(e l / l o s)$. La lectura clasificativa, autorizada por las marcas de indefinitud, se ve justificada por el hecho de admitirse la posibilidad de libros adicionales escritos en dicho año. La presencia del $\mathrm{AD}$ inferiría, por el contrario, que en ese periodo no habrá salido otro título de su autoría, y los libros aludidos fueron los únicos:

X y Y son los libros que escribió Borges en 1967.

“Crónicas de Bustos Domecq" es el libro que escribió Borges en 1967.

Conviene señalar que la libertad que presentan las oraciones copulativas en seleccionar la cuantificación de su predicado nominal se ve notablemente cohibida en construcciones con predicado verbal. Veamos dos oraciones con la misma cláusula que acabamos de comentar en la que está excluido el antecedente escueto en plural:

Estoy leyendo *(los) libros que escribió Dickens en 1867.

He recibido *(los) libros que escribió Dickens en 1867.

La (in)definitud legitimizada por presupuestos de exclusión e inclusión cuantificativa se ve fuertemente representada en todas las lenguas romances. La alternancia planteada arriba se puede apreciar con nitidez en grupos plurales como:

\footnotetext{
${ }^{6}$ No se percibe en una definitud así presentada ninguna información 'consabida' por los interlocutores.

${ }^{7}$ Una clase de libros escritos por Borges.
} 
Estos son inmigrantes que han entrado en España. [algunos]

Estos son los inmigrantes que entraron en España anoche a las 3 de la madrugada. [todos estos]

Hay que ser solidarios con los inmigrantes que han entrado en España. [todos]

Sabido es que la totalidad de ejemplares descritos que engloba el referente supone su identificación mental por parte de los hablantes. La vinculación del rasgo de unicidad con el de totalidad está presente en la teoría del artículo definido desde Hawkins: "La théorie de la localisation [...] ne s'applique pas seulement aux cas de référents connus du locuteur et de l'interlocuteur, mais prend également en charge les usages non familiers. Du côte quantificationnel, on notera la solution référentielle apportée au problème logique de l'unicité (ou totalité)" (Kleiber 1983: 90).

\section{OTROS FACTORES IDENTIFICADORES DE UNA SUBORDINADA RELATIVA}

Fuera de los factores expuestos, existen otras circunstancias que favorecen la lectura definida de un GN. Con la dimensión cuantitativa, estudiada en líneas anteriores, está en estrecha conexión el valor semántico que representa el predicado de la subordinada. Analícense las frases siguientes:

Una mujer que conoces salió con Bill anoche.

La mujer que amas salió con Bill anoche.

Recuerdo el día en que nació.

La variación del artículo supra se debe a la característica semántico-pragmática del predicado de la subordinada que impone una diferente dimensión numérica a su argumento-antecedente. El verbo conocer supone un conjunto de individuos afectados en función de complementos-objeto, en tanto que amar se relaciona normalmente con uno (se puede 'querer solo a una mujer' a la vez). Esta circunstancia incide en la descodificación de un único referente en la segunda secuencia. También el tercer sintagma cumple con la condición de unicidad, ya que uno nace en un solo día.

De acuerdo con lo señalado en la sección 2, podemos anticipar que las subordinadas adjetivas con estructura (semi)copulativa seleccionan GGNN indefinidos, como lo hacen las relativas con predicados no especificantes estativos: Me enamoré de una chica que \{tenía el pelo rubio / era muy lista\}. Las oraciones con tal estructura dan cuenta de las propiedades, calificación o juicios de valor relativos al núcleo nominal $\mathrm{y}$, por ello, es posible que se combinen con mayor frecuencia con antecedentes indefinidos (qué tipo $)^{8}$. Tales grupos han de aparecer con AI en su primera mención y no es habitual la alternancia cuantitativa que vimos en el apartado anterior:

\footnotetext{
${ }^{8}$ La posición más resistente a los GN escuetos es la de sujeto preverbal, reservada a segmentos determinados que funcionan como tema de la predicación.
} 
El actor escribió libros que fueron éxitos de ventas.

Escribió libros que se hicieron famosos.

El fenómeno se registra en textos que Lapesa considera como reales.

Me he encontrado con una excepción que me parece sumamente interesante.

Datos estadísticos parciales vienen a corroborar esta tesis. En un corpus CREA que hemos documentado con mil ejemplos, basado en diez GN selectos en plural ${ }^{9}$, las estructuras (semi)copulativas se han registrado en un $20,7 \%$ de las frases sin determinante, respecto a tan solo un $2,6 \%$ testimoniado en las de carácter definido.

Un importante elemento perturbador puede resultar también el aspecto morfológico que expresa el verbo de una relativa (y tal vez de la principal). Repárese en cómo una acción iterativa o durativa incide en la lectura definida o indefinida de su argumento y cómo una acción perfectiva tiende a prestarle la marca de definitud como la más preferible. Analícense casos de GGNN en plural:

Pruebo (las) medicinas que me trae Manuel.

Probé las medicinas que me trajo Manuel.

La joven pronunciaba (las) palabras que le dictaba su madre.

La joven pronunció las palabras que le dictó su madre.

Cuando entré, Pablo estaba contestando (las) preguntas que le hacian los periodistas.

Pablo contestó las preguntas que le hicieron los periodistas.

La misma relación se percibe en inglés, si bien su uso detallado puede diferir del castellano, p. ej. I usually read books that you do $\sim$ I read the books that you did (Diesing 1992: 75). La relación esbozada no es absoluta, aunque se atestigua una moderada tendencia a establecer conexión entre las categorías citadas. En todo caso, se necesitan estudios más profundos sobre la materia para poder extraer conclusiones definitivas.

La lectura definida puede derivarse asimismo de algunos adjuntos temporales que fijan el límite de una acción verbal o señalan el momento de su realización. Obsérvense las secuencias nominales siguientes que se introducen sin mención previa:

La biblioteca contiene libros que ha escrito Umberto Eco.

La biblioteca contiene los libros que Umberto Eco ha escrito hasta hoy.

Estoy leyendo libros que ha escrito Borges.

Estoy leyendo los libros que escribió Borges en 1976.

Tom Sawyer es un libro que leo de vez en cuando.

Tom Sawyer fue el libro que estaba leyendo cuando entró José.

\footnotetext{
${ }^{9} \mathrm{P}$. ej. opiniones que, conceptos que, etc.
} 
Otro factor que cabe tomar en cuenta, al estimar la referencia de un GN, es la negación que acompaña al verbo subordinado. Cotéjense dos parejas de frases:

El martes pasado, a primera hora de la mañana, recibí los libros que había encargado.

El martes pasado, a primera hora de la mañana, recibí libros que no había encargado.

Ellos no ven las cosas que ustedes ven.

Ellos ven cosas que ustedes no ven.

En suma, los verbos negados no suelen aportar información pertinente para la identificación de su argumento nominal sin contexto anafórico. Un estudio realizado por Pawlik (2019) demuestra que la negación en subordinadas precedidas del operador nulo aparece por término medio en un $16 \%$ de los casos examinados, comparado con un 2,6\% referido a las subordinadas con artículo definido ${ }^{10}$. Una diferencia apreciable que viene a confirmar nuestras previsiones.

\section{OBSERVACIONES FINALES}

El problema de la identificación del referente en los GN con oración de relativo es complicado y depende de muchos factores. Hemos demostrado que la lectura identificativa y no identificativa depende de condicionantes internos ${ }^{11}$ : semánticopragmáticos, léxicos y sintácticos, inherentes a la cláusula de relativo. Se perciben algunas diferencias en grupos plurales y singulares, se interpretan de forma un poco distinta los nombres contables y no contables, genéricos y no genéricos. En esta contribución hemos abordado solo algunas variables selectas capaces de imprimir la (in)definitud a un GN contable, básicamente no genérico, introducido en el discurso por primera vez. Se han sometido a examen únicamente las secuencias con el relativo que, el más frecuente de los nexos.

En el ámbito tratado, se ha mostrado que la permutabilidad referencial que ostenta el GN singular atiende a factores parecidos en español, francés e inglés. Así, se ha puesto de relieve que no son naturales los grupos indefinidos en construcciones cuyo predicado central tiene un carácter no especificante estativo, p. ej.: ?Una chica que encontré ayer en el cine ES GUAPA. Es admisible, en cambio, la indefinitud con predicados especificantes eventivos, como: Mañana VIENE A VERME una chica que encontré ayer en el cine. Del mismo modo, se recomiendan sin anáfora los grupos indefinidos con adjetivas estativas del tipo: UNA MUJER QUE HABLABA ESPAÑOL fue desagradable conmigo. Esta matización falta en estudios españoles dedicados a la materia.

\footnotetext{
${ }^{10}$ Son cifras relativas a una selección de GGNN en plural.

${ }^{11}$ Existen también variados factores externos que actúan desde fuera de la subordinada.
} 
Hemos subrayado el peso decisivo de la teoría de conjuntos (parcial/total) en la selección del artículo en un GN con modificador oracional. Un razonamiento deductivo nos lleva a la conclusión de que la presencia de los pronombres de segunda persona y algunos de tercera favorece el proceso de identificación del referente (lectura definida). A base de un examen estadístico, hemos demostrado un estatus especial de las oraciones copulativas frente a las de predicado verbal. Las primeras por su carácter predominantemente estativo se revelan más propensas a generar artículos indefinidos en sus cabezas. Hemos indicado también cierta relación que se percibe entre la (in)definitud de un GN y la forma negada del predicado en la subordinada.

Para un alumno polaco de ELE es importante darse cuenta de una gradación de la unicidad de referentes. He aquí un trío de oraciones en las que la cabeza de la cláusula relativa se hace cada vez más identificable en su primera aparición, conforme se acumulen datos identificativos relativos a la ubicación del referente en la esfera cognoscitiva del oyente:

Se trata de una película que echaron ayer.

Se trata de una película que echaron ayer en TE.

Se trata de la película que echaron ayer, a las 20.00, en TE2.

En general, los predicados complejos que localizan el referente en las coordenadas espacio-temporales junto a un punto de mira reconocible, aseguran mejor el esperado grado de unicidad contextual para su antecedente. 


\section{BIBLIOGRAFÍA}

ASALE (2009). Nueva gramática de la lengua española. Madrid: Espasa Libros.

ASALEM (2010). Nueva gramática de la lengua española. Manual. Madrid: Espasa Libros.

Brucart, J.M. (1999). La estructura del sintagma nominal: las oraciones de relativo. In I. Bosque, V. Demonte (eds.), Gramática descriptiva de la lengua española (pp. 395-522). Madrid: Espasa-Calpe.

Carlson, G.N. (1980). Reference to Kinds in English. New York: Garland Publishing.

Corblin, F. (1987). Indéfini, défini et démonstratif. Genève/Paris: Librairie Droz.

CREA, Banco de datos [en línea]. Corpus de referencia del español actual, <http://www.rae.es> [fecha de la consulta: 22.10.2018].

Diesing, M. (1992). Indefinites. Cambridge: MIT Press.

Fernández Leborans, M.J. (1999). La predicación. Las oraciones copulativas. In I. Bosque, V. Demonte (eds.), Gramática descriptiva de la lengua española (pp. 2357-2460). Madrid: Espasa-Calpe.

Hawkins, J. (1978). Definiteness and Indefiniteness. A study in Reference and Grammaticality Prediction. London: Croom Helm.

Kleiber, G. (1981). Relatives spécifiantes et relatives non spécifiantes. Le Français Moderne, 49, 216-233.

Kleiber, G. (1983). Article défini, théorie de la localisation et presupposition existentielle. Langue Française, 57, 87-105.

Leonetti, M. (1991). La noción de tema y la interpretación de los indefinidos. Epos, VII, 165-181.

Leonetti, M. (1999a). Los determinantes. Madrid: ArcoLibros.

Leonetti, M. (1999b). El artículo. In I. Bosque, V. Demonte (eds.), Gramática descriptiva de la lengua española (pp. 787-889). Madrid: Espasa-Calpe.

Leonetti, M. (2012). Indefiniteness and Specificity. In J.I. Hualde, A. Olarrea y E. O'Rourke (eds.), Handbook of Spanish Linguistics (pp. 285-305). Oxford: Blackwell.

Leonetti, M. (2013). On contrastive readings in the interpretation of NPs/DPs. In S. Chiriacescu (ed.), Proceedings of thr VI Nereus International Workshop ,"Theoretical implications at the syntax-semantics interface in Romance”. Arbeitspapier 127 (pp. 99-116). Universität Konstanz.

Lyons, C. (1999). Definiteness. Cambridge: Cambridge University Press.

Milsark, G. (1974). Existential sentences in English. Ph. D dissertation. MIT.

Milsark, G. (1977). Toward the explanation of certain peculiarities of the existential construction in English. Linguistic Analysis, 3, 1-29.

Pawlik, J. (2019). Oraciones de relativo como modificadores referenciales de un GN. In Tomo en homenaje al prof. W. Nowikow. Łódź: Wydawnictwo Uniwersytetu Łódzkiego.

Riley, J.A. (2008). Mental Representations. Reference and Definiteness. Alexandria: Elromani.

Wilmet, M. (1986). La détermination nominale. Paris: Presses Universitaire de France. 